\title{
Evidence for inbreeding depression and post-pollination selection against inbreeding in the dioecious plant Silene latifolia
}

\author{
S Teixeira ${ }^{1,2,3}$, K Foerster ${ }^{1}$ and G Bernasconi ${ }^{1,4}$ \\ ${ }^{1}$ Department of Ecology and Evolution, University of Lausanne, Lausanne, Switzerland and ${ }^{2}$ Institute of environmental Sciences, \\ University of Zurich, Zurich, Switzerland
}

\begin{abstract}
In many species, inbred individuals have reduced fitness. In plants with limited pollen and seed dispersal, post-pollination selection may reduce biparental inbreeding, but knowledge on the prevalence and importance of pollen competition or post-pollination selection after non-self pollination is scarce. We tested whether post-pollination selection favours less related pollen donors and reduces inbreeding in the dioecious plant Silene latifolia. We crossed 20 plants with pollen from a sibling and an unrelated male, and with a mix of both. We found significant inbreeding depression on vegetative growth, age at first flowering and total fitness $(22 \%$ in males and $14 \%$ in females). In mixed pollinations, the
\end{abstract}

unrelated male sired on average $57 \%$ of the offspring. The greater the paternity share of the unrelated sire, the larger the difference in relatedness of the two males to the female. The effect of genetic similarity on paternity is consistent with predictions for post-pollination selection, although paternity, at least in some crosses, may be affected by additional factors. Our data show that in plant systems with inbreeding depression, such as $S$. latifolia, pollen or embryo selection after multiple-donor pollination may indeed reduce inbreeding.

Heredity (2009) 102, 101-112; doi:10.1038/hdy.2008.86; published online 13 August 2008

Keywords: seed paternity; microsatellite DNA; sexual selection; pollen competition; inbreeding avoidance; relatedness

\section{Introduction}

Inbreeding can reduce the fitness of inbred relative to outbred offspring (inbreeding depression; Charlesworth and Charlesworth, 1987; Husband and Schemske, 1996). Inbreeding depression results from the increase of homozygous loci in inbred progeny through two possible mechanisms: (a) if heterozygotes at a given locus have an inherent fitness advantage over homozygotes (overdominance) and (b) if the effects of recessive (or partly recessive) deleterious alleles are masked by dominant alleles (partial dominance) in heterozygote individuals. The relative importance of partial dominance and overdominance in natural populations is largely unknown (Charlesworth and Charlesworth, 1987; Carr and Dudash, 2003). However, studies of Eichhornia, Amsinkia and Mimulus found support for inbreeding depression based on partial dominance (Dudash and Carr, 1998). Expression of lethal or severely deleterious recessive alleles is likely to occur in the early life stages and may result for instance in seed abortion or seedling mortality, whereas less deleterious alleles may

Correspondence: Professor G Bernasconi, Institute of Biology, University of Neuchatel, Rue Emile Argand 11, Neuchatel 2009, Switzerland.

E-mail: giorgina.bernasconi@unine.ch

${ }^{3}$ Current address: University of Algarve, CCMAR, MAREE, Faro 8005-139, Portugal.

${ }^{4}$ Current address: Institute of Biology, University of Neuchatel, Neuchatel 2009, Switzerland.

Received 28 March 2008; revised 11 July 2008; accepted 18 July 2008; published online 13 August 2008 accumulate and decrease plant fitness later in the life cycle by reducing growth rate or reproduction (Lande and Schemske, 1985).

Inbreeding depression has a major impact under natural conditions (Keller and Waller, 2002). Negative effects of inbreeding on reproductive traits and offspring establishment have been documented in several plant species (for example, Richards, 2000; Fishman, 2001). Because of the detrimental effects of inbreeding on fitness, mechanisms should arise to avoid fertilizations by related pollen (Bernasconi et al., 2003, 2004), as has been found in some animal species, where unrelated males are preferred at mating (for example, Hoffman et al., 2007) or fertilization (Foerster et al., 2006; Simmons et al., 2006). In many plant species, seeds disperse over short distances from the maternal plant, and neighbouring individuals are thus likely to be related and to exchange pollen among each other due to restricted movement of pollinators. Accordingly, several experimental studies confirmed that crosses between distantly growing plants result in fitter offspring than crosses between neighbouring individuals (reviewed by Delph, 2004). Most of these studies applied singledonor pollination. However, natural pollen loads may commonly contain pollen from multiple pollen donors (reviewed by Bernasconi, 2003; Mitchell et al., 2005), a condition that provides the opportunity for post-pollination inbreeding avoidance.

Pollen tubes express many genes (for example, Becker et al., 2003), which may allow for recognition between related alleles during pollen-pistil interactions. In addition to the well-studied case of genetic self-incompatibility 
systems (Nasrallah, 2002), several studies suggest that genetically based pollen-pistil interactions occur also in self-compatible species (Bateman, 1956). In Zea mais, Dianthus chinensis, Clarckia gracilis, Silene nutans and S. vulgaris, there is evidence for selection against self-pollen (Pfahler, 1965; Aizen et al., 1990; Jones, 1994; Hauser and Siegismund, 2000; Glaettli et al., 2006). Such genetic mechanisms provide the potential for relatedness-based post-pollination pollen selection by the recipient plant (Waser and Price, 1993). When several pollen tubes from different donors grow through the stigma to reach the ovary, the receiving maternal plant may favour pollen from less related donor plants. Alternatively or in addition to pollen selection, seeds may be affected by heterosis or be aborted selectively depending on donor-recipient relatedness resulting in post-pollination selection. Although the relative importance of pre- and post-zygotic mechanisms may vary, there are some cases where pollen selection has been shown to be more important than embryo selection (Cruzan and Barrett, 1996; Hauser and Siegismund, 2000).

Most of the current knowledge on inbreeding depression and pollen discrimination in plants stems from studies of selfing (uniparental inbreeding). In this study, we aimed at widening this view by investigating mating between relatives (biparental inbreeding) in the dioecious white campion (Silene latifolia). This species shows limited seed dispersal and restricted pollen transfer among neighbouring plants (McCauley, 1997; Wright and Meagher, 2004; M Barluenga et al. unpublished data). Inbreeding is probably common, and Richards (2000) showed that $S$. latifolia sustains inbreeding depression on seed germination. Also, pollen competition is likely in this species: in an earlier study, we detected frequent multiple paternity within fruits (Teixeira and Bernasconi, 2007). S. latifolia may hence have developed a postpollination selection mechanism to reduce inbreeding. The aims of this study were (i) to estimate the costs of inbreeding at various life-cycle stages in S. latifolia and (ii) to test whether inbreeding is reduced through a paternity bias in response to the genetic similarity between pollen donors and the maternal plant.

We conducted controlled crosses in S. latifolia. We pollinated replicate flowers within female plants using pollen from a related male, from an unrelated male or both. Then, we measured the fitness of offspring resulting from these crosses at the seed stage, during early growth, and during flower and fruit production. If there is inbreeding depression for some traits, we expect outbred offspring to perform better than inbred offspring. Finally, we determined the relative paternity success of the related and the unrelated male in crosses with mixed pollen, with the help of molecular markers. If post-pollination selection against related pollen or inbred embryos occurs, we expect paternity to be biased towards the unrelated pollen donor, and this effect may depend on the genetic similarity between the maternal plant and the pollen donors.

\section{Materials and methods}

\section{Study species and field collection}

The white campion, S. latifolia (Poiret) $(=S$. alba (Miller) Krause, = Melandrium album (Miller) Garcke), is a diploid $(2 n=24)$ member of the carnation family, Caryophylla- ceae. It is a dioecious, insect-pollinated and short-lived perennial native to Europe and parts of Asia. In September 2003, we collected seeds in Village-Neuf on the banks of the Huningue canal (France, $47^{\circ} 36^{\prime} 25^{\prime \prime} \mathrm{N}$; $7^{\circ} 33^{\prime} 31 \mathrm{E} ; 245 \mathrm{~m}$ a.s.1.). The population had an estimated size of 80 flowering individuals, occupying an area of $350 \times 25 \mathrm{~m}$. We sampled one fruit (seed capsule) from each of 15 different female plants located at least $2 \mathrm{~m}$ apart from each other. We previously detected significant and frequent multiple paternity within fruits after natural pollination in this population, with an average of 3.4 pollen donors (s.d. $=1.6$ ) among 20 offspring per fruit (Teixeira and Bernasconi, 2007).

\section{Plant rearing and experimental pollination}

In March 2004, we germinated 20 seeds per fruit $(N=300$ seeds in total) in Petri dishes $(\varnothing 90 \mathrm{~mm}$, lined with cotton and filter paper, and damped with $1 \mathrm{mM}$ giberellic acid) in a growth cabinet $\left(21^{\circ} \mathrm{C}, 70 \% \mathrm{RH}, 16 \mathrm{~h}\right.$ day and $8 \mathrm{~h}$ night). After 21 days, we repotted the seedlings $(N=294)$ in $10 \mathrm{~cm}$ pots, using a 3:1 mixture of soil (Treff BF4 from GVZ-Bolltec Zurich, Switzerland) and sand, and kept them in an insect-free greenhouse $\left(23 \pm 2{ }^{\circ} \mathrm{C} /\right.$ $18 \pm 1{ }^{\circ} \mathrm{C}$ during day/night, $\mathrm{RH}=55 \pm 10 \%$, artificial light by sodium lamps for $16 \mathrm{hday}^{-1}$, plus natural light). Plants were placed at random positions within the greenhouse. After all plants had flowered, we selected 20 female and 36 male plants for crosses, stemming from 12 (out of the 15) field-collected seed families. We chose one to two female plants per seed family. For each female plant, we selected one brother (stemming from the same field-collected fruit, that is, a full- or half-brother, as seed families in the field are often fathered by more than one pollen donor; Teixeira and Bernasconi, 2007) and one unrelated male (stemming from a different field-collected fruit from the same population). Each male was crossed with only one female, except for four males, which we had to use twice, because no other male plant flowered in time. A detailed scheme of the crossing design is provided as Supplementary Information.

We hand pollinated three sequentially opening flowers on each female with either pollen from her brother, pollen from an unrelated male or a 1:1 mixture of the two, randomizing the order of the treatments (Figure 1). We applied pollen from anthers that had dehisced in the previous $36 \mathrm{~h}$, directly to the stigma (24h after flower opening), by rubbing the anthers on the entire stigma surface, starting from the base to the tip. In mixed pollinations, the anthers from each male were held together and rubbed simultaneously on the stigma. After pollination, the flowers were bagged to ensure collection of all seeds when the fruit would open. We sowed a random subset of 20 seeds per fruit in Jiffy peat pellets under greenhouse conditions, and after 21 days, we repotted the seedlings as described above.

\section{Measurement of fitness traits}

We measured 11 different fitness traits. Total seed number (1) and total seed mass in milligrams (2) were measured for each fruit that we obtained from controlled crosses. The sample size was 60 fruits: three pollination treatment levels (flowers) $\times 20$ maternal plants. We calculated individual seed mass (3) as the total seed mass divided by the number of seeds. We recorded germination success 


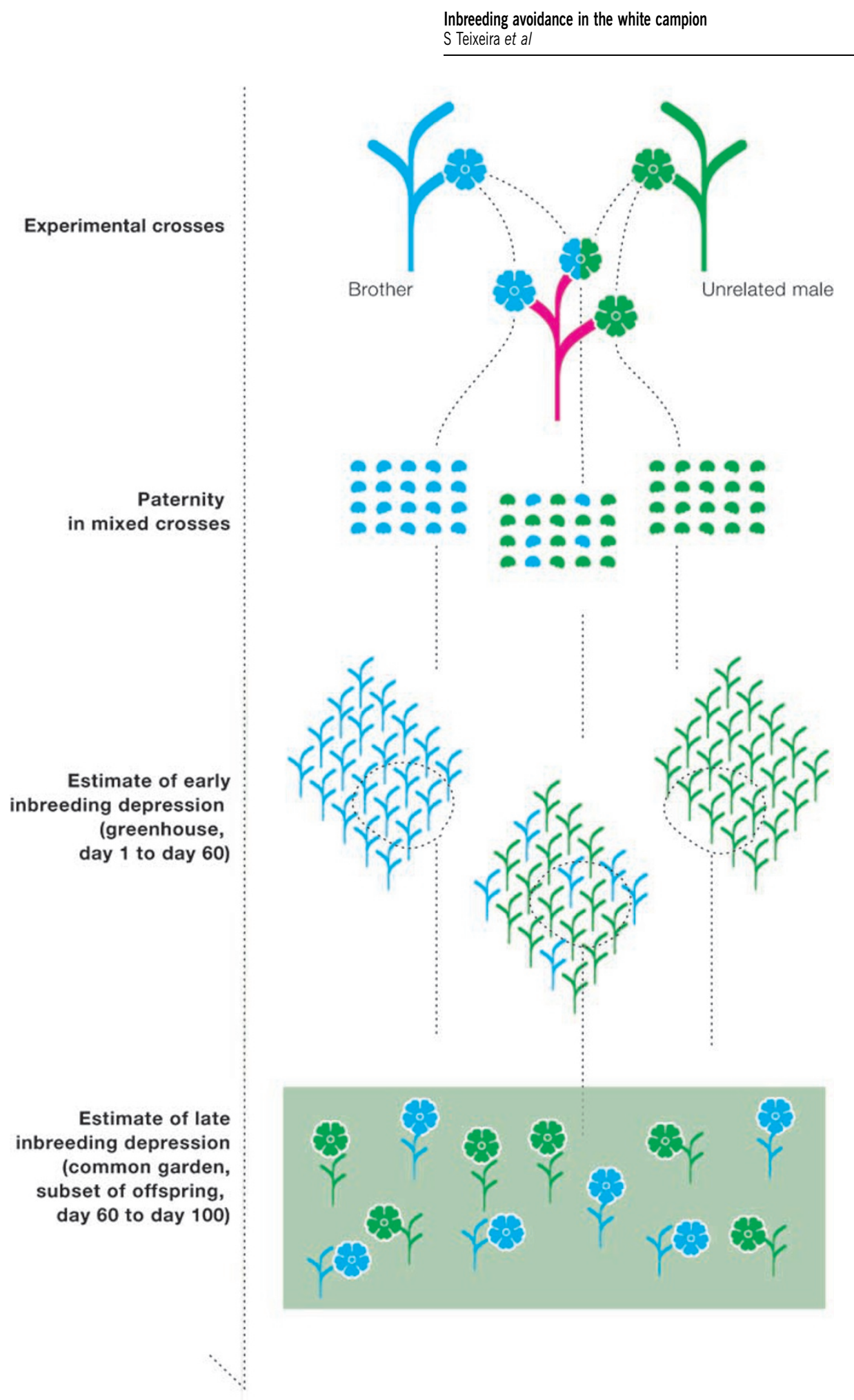

Figure 1 Experimental design to test for post-pollination inbreeding avoidance and to quantify inbreeding depression in Silene latifolia. Three distinct flowers on each female received pollen from a related male (brother), pollen from an unrelated male or a 1:1 mixture of pollen from both donors. Thereafter, paternity in mixed-donor pollinations was assessed using molecular markers, and offspring fitness was quantified in the greenhouse (up to day 60 from sowing) and in a common garden (days 60 to 100).

(yes/no; 4) for 20 seeds per fruit (five seeds were lost during sowing, so germination was determined for a total of 1195 seeds). Germination time (5) was the number of days from sowing to germination. All germinated and surviving offspring were kept under greenhouse conditions. On days 21 and 60 from sowing, we measured stem height $(\mathrm{cm})$ and leaf development (number of leaves on day 21, and length of the longest leaf in centimetre on day 60 ). The first principal component of the size measures on day 21 explained $86.7 \%$ of the variance in stem height and leaf number and was used as the measure of vegetative growth day 21 (6). The first 
principal component of the measures on day 60 explained $98.2 \%$ of the variance in stem height and leaf length (although it was mainly determined by stem height), and we used this as the measure of vegetative growth day 60 (7). We did not centre the principal components to zero mean, to avoid negative values in these fitness traits. Age at flowering (8) was the number of days from germination to the day when the first flower opened.

From day 60 until day 100 after sowing, during the months of June and July, we placed four female and two male offspring per treatment in a common garden. The sample size was 360 offspring: 6 offspring $\times 3$ pollination treatment levels $\times 20$ maternal plants. The plants were repotted $(\varnothing 18 \mathrm{~cm}$ pots) with the soil mixture described above. We placed the pots at $75 \mathrm{~cm}$ distance from each other on a flat surface covered by vegetation, which had been mown before the experiment. We watered the plants daily. The study plot was surrounded by natural stands of S. latifolia (flowering from May to October), in which we previously recorded the specialist pollinator and seed predator Hadena bicruris (Noctuidae). The experimental plants could be accessed by pollinators and herbivores. The plants began flowering between 28 days before and 6 days after the start of the exposure (median $=14$ days before). At weekly intervals, we counted the flowers and new fruits on all experimental plants. Fruits were marked to avoid double counting. Flower longevity is 2 days in S. latifolia males, and 5-7 days in unpollinated female flowers. Weekly censuses ensure that novel flowers are counted each time, although this method underestimates total flower production, as flowers opening and dehiscing between census days are not recorded. For all plants that survived to day 100, we calculated the total number of flowers (9) and number of fruits (10) as the sum of the weekly counts. At the end of the 6th week, we harvested all plants, dried them to weight constancy $\left(30^{\circ} \mathrm{C}, 2\right.$ weeks) and determined the total dry biomass (11) of all aboveground material. Effects of the pollination treatment on offspring sex ratios are reported elsewhere (Teixeira and Bernasconi, 2008).

\section{Microsatellite DNA paternity analysis}

We extracted genomic DNA from leaf tissue of the parents $(N=56)$ and offspring $(N=20$ offspring from each of the 20 two-donor crosses $=400-87$, not germinated seeds $=313$ ). We extracted parental DNA applying the CTAB method (Doyle and Doyle, 1990), and offspring DNA using the Macherey-Nagel Nucleospin Plant Kit. The extracted DNA was run on $0.8 \%$ agarose gels to optimize dilutions for a final concentration of $10 \mathrm{ng} \mu \mathrm{l}^{-1}$. We typed all individuals at three microsatellite loci (S14, S16 and S18), following the procedures described by Teixeira and Bernasconi (2007). These loci were previously found to be highly polymorphic in six natural populations of European S. latifolia (Jolivet and Bernasconi, 2007). We assigned paternity by comparing each offspring genotype to the maternal genotype and the two potential paternal genotypes. Offspring that did not germinate $(N=87)$ could not be typed, and for some of the germinated offspring, DNA amplification failed $(N=39)$. We succeeded in determining the paternity of 274 offspring.

\section{Estimation of genetic relatedness}

On the basis of the microsatellite genotypes of all parental plants, we calculated estimates of genetic relatedness $r$ (Queller and Goodnight, 1989), with the program SPAGEDI 1.1b (Hardy and Vekemans, 2002). We used genotypic data from 27 field-collected plants (Jolivet and Bernasconi, 2007) to calculate population allele frequencies for the three microstellite loci. We estimated Queller and Goodnight's $r$ of each maternal plant to its related and unrelated mating partner. From here onwards, we refer to this estimator as 'relatedness'. In two brothers and two unrelated males, several null alleles prevented the estimation of a meaningful value of relatedness. The sample sizes were therefore 18 for the relatedness of mothers to brothers, 18 for the relatedness of mothers to unrelated pollen donors and 16 for the difference in relatedness of mothers to unrelated and related mating partners. The mean relatedness of mothers to their brothers was $0.45 \pm 0.38$ s.d. (range: $-0.21-1.00)$, and to the unrelated pollen donors it was $-0.12 \pm 0.28$ s.d. (range: $-0.40-0.44$ ). These estimated values of relatedness are approximations to pedigree relatedness and the exact values depend on the involved allele frequencies. Queller and Goodnight's $r$ differs from true probabilities of identity by descent in that it can take negative values. A negative value means that the allele frequencies of the two individuals differ from the population mean in opposite directions (Queller and Goodnight, 1989). As we had only three microsatellite markers available, our estimates of relatedness show considerable sampling variance. We assume however that this error is unbiased with respect to our working hypotheses. As expected, a Wilcoxon matched-pairs test showed that within females the relatedness with brothers was significantly larger than the relatedness with unrelated males $(N=16, W=1, P<0.001)$.

\section{Data analysis}

Continuous data are summarized as mean \pm s.d., count data as median, range. We present two-tailed tests, which were performed using Genstat 10.3 (Lawes Agricultural Trust, Rothamsted Experimental Station, Harpenden, UK) and SPSS 14.0 (SPSS Inc., Chicago, IL, USA).

Fitness data: We analyzed data on seed production (seed number and seed mass) using repeated-measures ANOVA with pollen donor treatment (single-donor brother, single-donor unrelated, two-donor) as withinsubject factor (repeated measures). All other fitness data showed a less balanced design matrix, due to losses during the course of the experiment. We therefore analyzed these data in linear mixed models (LMMs), only germination success was analyzed in a generalized LMM with binomial error. Germination time, age at flowering and number of flowers deviated from a normal distribution, and we logtransformed these variables $(y=10 \times \log (x+0.5))$ to approximate a normal distribution. We accounted for repeated measures on maternal plants through a random factor of maternal identity. The fixed model contained factors for the two treatment effects, pollen donor (brother, unrelated male) and pollen donor number (single-donor, two-donor) and their interaction. Additional fixed factors were the sex of the offspring and its interaction with pollen donor, the maternal field family and the paternal field family. The field family refers to the field-collected seed 
family from which parental plants originated. For each fitness trait, we reduced the full model stepwise by eliminating fixed factors with $P>0.1$, and we retested all eliminated factors by adding them one by one to the final model. We report effect sizes, F statistics and error probabilities of F-tests from the final model. We examined the residuals of each final model to ensure that they met the requirements of normality. In the multivariate LMM of fitness, we modelled seven dependent variables: germination time, vegetative growth day 21, vegetative growth day 60, age at flowering, number of flowers, number of fruits and total dry biomass. We started from the same full model as in the univariate analyses, and report Wald statistics and probabilities from the final model.

Inbreeding depression: We calculated inbreeding depression $(\delta)$ on each fitness trait from the phenotypic difference between the fitness of outbred progeny sired by the unrelated pollen donor $\left(W_{\mathrm{O}}\right)$ and inbred progeny sired by the (half-) brother $\left(W_{\mathrm{I}}\right)$ using a modification of Lande and Schemske (1985) formula given by Ågren and Schemske (1993), which varies in $[-1,1]$ :

$$
\delta=\left(W_{\mathrm{O}}-W_{\mathrm{I}}\right) / W_{\max } \text {, whereby } W_{\max }=\max \left(W_{\mathrm{O}}, W_{\mathrm{I}}\right) \text {. }
$$

Positive values of $\delta$ indicate a superiority of outbred over inbred progeny. For germination time and age at flowering, smaller values indicate higher fitness. We therefore multiplied $\delta$ of these traits by -1 . We calculated inbreeding depression for each fitness trait and family and then averaged $\delta$ over families. Finally, we calculated inbreeding depression on a measure of total fitness for inand outbred progeny within each family. We determined the total flowering time of each plant as: 100 days (the duration of the experiment)_germination time-age at flowering. The average daily reproductive output in females was estimated as the total number of fruits per 40 days (the duration of exposure in the common garden). In males, we quantified reproductive output as the total number of flowers per 40 days. Total fitness was then calculated as: probability of germination $\times$ total flowering time $\times$ average daily reproductive output.

Paternity bias: We applied generalized LMMs with binomial error to test for an effect of parental relatedness on the paternity success of brothers and unrelated males. Of the 400 sown seeds from the twodonor treatment, 87 did not germinate. If germination success depends on the genetic relatedness between the parents (that is, if more homozygous offspring are less likely to germinate), this could bias our results in favour of the hypothesis that genetic relatedness of the father to the recipient plant affects his pollination success. Thus, for a more conservative analysis, we assigned all seeds that failed to germinate in the two-donor crosses to the brother and the unrelated male, according to the germination successes in the single-donor crosses. For each maternal plant, we estimated seed germination probability under inbreeding, $\mathrm{P}_{\mathrm{GI}}$, from the single-donor cross with the brother. We also measured seed germination probability under outbreeding, $\mathrm{P}_{\mathrm{GO}}$, from the single-donor cross with the unrelated male. We then estimated the number of failed seeds fathered by the unrelated male as

$$
N_{\text {failed }} /\left(1+\left(\mathrm{P}_{\mathrm{GO}} / \mathrm{P}_{\mathrm{GI}}\right)\right)
$$

where $N_{\text {failed }}$ was the number of seeds that failed to germinate in each two-donor cross. We added this value to the number of offspring that were assigned to the unrelated male through microsatellite paternity analysis, and reran our analysis of a potential paternity bias. In a final step, we assigned all non-germinated seeds to the brother, for the most conservative analysis.

\section{Results}

\section{Pollination treatment effects}

Although more seeds were produced after outbred than inbred pollination (Table 1), there was no significant difference in seed number between pollen donor treatments (brother, mixed or unrelated pollen donor; repeated measures ANOVA, within subject effect: $\left.\mathrm{F}_{2,18}=1.00, P=0.377\right)$. Similarly, there was no effect of the pollen donor treatment on total seed mass $\left(F_{2,18}=2.00, P=0.150\right)$. Seed number and total seed mass were positively correlated in all treatment groups (all Pearson's $r \geqslant 0.88$, all $P<0.01, N=20$ in each group). Average individual seed mass was also not significantly affected by pollen donor treatment $\left(\mathrm{F}_{2,18}=0.78\right.$, $P=0.465)$.

Of the 1195 planted seeds, 934 germinated successfully (78.2\%), and $895(74.9 \%)$ survived to day 60, when the second set of growth measurements were taken. Outbred seeds were not more likely to germinate, but they showed a tendency to germinate within a shorter time period (Table 2). Young plants fathered by the unrelated male were taller and grew more leaves (principal components of growth measurements on day 21), and they produced larger leaves (day 60, Table 2) than the young plants fathered by the related male. Out of the 895 surviving plants, 880 flowered $(98.3 \%)$, and of these, 342 were exposed to the common garden environment between days 60 and 100. Pollen donor identity affected the age at which plants started to flower: outbred individuals had a shorter time span between germination and onset of flowering than inbred individuals (Table 2). This effect tended to differ between male and

Table 1 Offspring fitness from inbred and outbred experimental crosses in S. latifolia

\begin{tabular}{lcr}
\hline Trait & $\begin{array}{c}\text { Inbred cross } \\
\text { with brother }\end{array}$ & $\begin{array}{c}\text { Outbred cross } \\
\text { with unrelated } \\
\text { male }\end{array}$ \\
\hline Number of seeds & $230(24-392)$ & $235(94-382)$ \\
Total seed mass (mg) & $144.42(81.60)$ & $179.93(81.00)$ \\
Individual seed mass (mg) & $0.72(0.19)$ & $0.76(0.18)$ \\
Germination success & $0.80(0.40)$ & $0.87(0.34)$ \\
Germination time males (days) & $7(5-23)$ & $7(5-22)$ \\
Germination time females (days) & $7(5-23)$ & $7(3-21)$ \\
Vegetative growth day 21 & $7.09(3.14)$ & $7.84(3.37)$ \\
Vegetative growth day 60 & $55.56(14.80)$ & $58.15(12.52)$ \\
Age at flowering males (days) & $40(23-69)$ & $38(23-54)$ \\
Age at flowering females (days) & $36(27-66)$ & $36(27-59)$ \\
Number of flowers males & $56(11-117)$ & $59.5(4-126)$ \\
Number of flowers females & $7(1-19)$ & $7(2-13)$ \\
Number of fruits females & $23(4-51)$ & $24(5-45)$ \\
Total dry biomass males (mg) & $22.41(1.89)$ & $22.39(2.18)$ \\
Total dry biomass females (mg) & $27.33(3.08)$ & $27.76(3.32)$ \\
\hline
\end{tabular}

Shown are means (s.d.) for continuous variables, and medians (range) for count data. Vegetative growth is defined as the first principal component of size measures (see Materials and methods). 
Table 2 Effects of pollen donor identity (brother versus unrelated male) on offspring fitness traits

\begin{tabular}{|c|c|c|c|c|c|c|c|c|c|c|}
\hline \multirow[t]{2}{*}{ Trait } & \multicolumn{2}{|c|}{$\mathrm{N}$} & \multicolumn{3}{|c|}{ Random model } & \multicolumn{5}{|c|}{ Fixed model } \\
\hline & Offspring & $\begin{array}{c}\text { Maternal } \\
\text { plants }\end{array}$ & $\begin{array}{c}\text { Variance } \\
\text { mother } \pm \text { s.e. }\end{array}$ & $T_{1, \infty}$ & $\mathrm{P}$ & Fixed effects & Effect size ${ }^{\mathrm{a}}$ & $D F$ & F statistic & $\mathrm{P}$ \\
\hline \multicolumn{11}{|l|}{ Early fitness } \\
\hline Germination success $^{b}$ & 1195 & 20 & $1.05 \pm 0.05$ & 2.43 & 0.02 & $\begin{array}{l}\text { Pollen donor } \\
\text { Paternal family }\end{array}$ & 0.31 & $\begin{array}{c}1 ; 594.4 \\
12 ; 392.6\end{array}$ & $\begin{array}{l}1.43 \\
2.93\end{array}$ & $\begin{array}{r}0.231 \\
<0.001\end{array}$ \\
\hline Germination time (days) & 934 & 20 & $0.47 \pm 0.18$ & 2.61 & 0.01 & $\begin{array}{l}\text { Pollen donor } \\
\text { Sex } \\
\text { Paternal family }\end{array}$ & $\begin{array}{l}-1.05 \\
-0.945\end{array}$ & $\begin{array}{c}1 ; 792.8 \\
1 ; 825.2 \\
12 ; 386.4\end{array}$ & $\begin{array}{l}3.70 \\
3.28 \\
1.78\end{array}$ & $\begin{array}{l}0.073 \\
0.071 \\
0.050\end{array}$ \\
\hline Vegetative growth day 21 & 891 & 20 & $3.31 \pm 1.19$ & 2.79 & 0.01 & $\begin{array}{l}\text { Pollen donor } \\
\text { Paternal family }\end{array}$ & 0.71 & $\begin{array}{c}1 ; 832.7 \\
12 ; 564.1\end{array}$ & $\begin{array}{r}10.59 \\
3.28\end{array}$ & $\begin{array}{r}0.001 \\
<0.001\end{array}$ \\
\hline Vegetative growth day 60 & 895 & 20 & $12.80 \pm 6.8$ & 1.88 & 0.060 & $\begin{array}{l}\text { Pollen donor } \\
\text { Paternal family }\end{array}$ & 2.71 & $\begin{array}{c}1 ; 652.1 \\
12 ; 124.7\end{array}$ & $\begin{array}{l}6.68 \\
2.62\end{array}$ & $\begin{array}{l}0.010 \\
0.004\end{array}$ \\
\hline \multicolumn{11}{|l|}{ Late fitness } \\
\hline Age at flowering (days) & 880 & 20 & $0.025 \pm 0.011$ & 2.29 & 0.02 & $\begin{array}{l}\text { Pollen donor } \\
\text { Sex } \\
\text { Pollen donor } \times \text { sex }\end{array}$ & $\begin{array}{r}-0.52 \\
0.55 \\
-0.54\end{array}$ & $\begin{array}{c}1 ; 849.1 \\
1 ; 840.3 \\
1 ; 840\end{array}$ & $\begin{array}{r}11.90 \\
11.84 \\
3.64\end{array}$ & $\begin{array}{r}<0.001 \\
<0.001 \\
0.057\end{array}$ \\
\hline Total number of flowers & 329 & 20 & $0.41 \pm 0.29$ & 1.4 & 0.16 & $\begin{array}{l}\text { Pollen Donor } \\
\text { Sex } \\
\text { Paternal family }\end{array}$ & $\begin{array}{l}0.48 \\
7.170\end{array}$ & $\begin{array}{l}1 ; 291.8 \\
1 ; 300.9 \\
12 ; 75.6\end{array}$ & $\begin{array}{r}0.15 \\
1152.21 \\
1.83\end{array}$ & $\begin{array}{r}0.698 \\
<0.001 \\
0.058\end{array}$ \\
\hline Total number of fruits & 221 & 20 & $4.69 \pm 5.30$ & 0.89 & 0.38 & $\begin{array}{l}\text { Pollen donor } \\
\text { Paternal family }\end{array}$ & 0.39 & $\begin{array}{l}1 ; 191.0 \\
12 ; 46.1\end{array}$ & $\begin{array}{l}0.08 \\
1.97\end{array}$ & $\begin{array}{l}0.784 \\
0.050\end{array}$ \\
\hline Total dry biomass (mg) & 328 & 20 & 0 & - & - & $\begin{array}{l}\text { Pollen donor } \\
\text { Sex } \\
\text { Maternal family }\end{array}$ & $\begin{array}{r}0.33 \\
-5.17\end{array}$ & $\begin{array}{c}1 ; 305.0 \\
1 ; 305.0 \\
11 ; 305.0\end{array}$ & $\begin{array}{r}0.79 \\
234.63 \\
2.17\end{array}$ & $\begin{array}{r}0.374 \\
<0.001 \\
0.016\end{array}$ \\
\hline Multivariate model & & & & & & Fixed effects & & $D F$ & Wald & $\mathrm{P}$ \\
\hline Multivariate fitness & 934 & 20 & & & & $\begin{array}{l}\text { Pollen donor } \\
\text { Sex } \\
\text { Paternal family } \\
\text { Pollen donor } \times \text { sex }\end{array}$ & & $\begin{array}{l}14 \\
10 \\
90 \\
18\end{array}$ & $\begin{array}{r}56.39 \\
1214.26 \\
191.29 \\
33.46\end{array}$ & $\begin{array}{r}<0.001 \\
<0.001 \\
<0.001 \\
0.015\end{array}$ \\
\hline
\end{tabular}

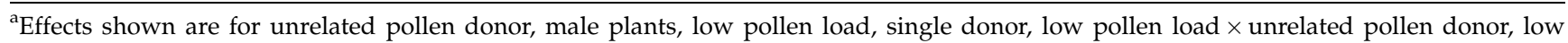
pollen load $\times$ single donor and male $\times$ unrelated pollen donor.

For log-transformed traits, effect sizes are back-transformed to the original scale.

${ }^{\mathrm{b}}$ Generalized linear mixed model with binomial error, scale parameter $=0.978$.

We used linear mixed models with maternal plant as a random factor, and also tested for effects of donor number (one versus two donors), offspring sex and maternal and paternal family.

female plants (interaction between donor identity and sex). Among males, outbred individuals flowered at an earlier age than inbred individuals (Table 1), whereas this difference was not apparent among females. All other late fitness components (the number of flowers or fruits produced, and the total dry biomass) were not significantly affected by pollen donor identity (see Table 2). The number of pollen donors (single donor or mixed pollination) did not affect any of the investigated fitness traits (Table 2).

\section{Effects of offspring sex and parental family}

Male seeds tended to germinate more quickly than female seeds (Table 2). There was no sex difference in any of the vegetative growth parameters, but female plants started to flower earlier than male plants (Table 2). As expected for this sexually dimorph species, male plants produced more flowers than female plants (Table 2). Finally, female plants had a larger final dry biomass, probably due to the fruit production (Table 2). The identity of the paternal family (that is, the field sampled fruit where the paternal plant originated from) had a significant effect on all offspring fitness components, except the age at flowering and final dry biomass
(Table 2). Maternal family showed a significant effect only on final dry biomass (Table 2).

\section{Multivariate analysis of fitness effects}

Separate tests on all fitness components are not entirely independent, because some of these traits were correlated (Table 3). Seeds that germinated more quickly produced plants with stronger vegetative growth on day 21 , and this growth measurement also correlated with an earlier onset of flowering. Male plants with greater stem height and longer leaves on day 60 had a larger final dry biomass. In female plants, however, this growth measure was negatively correlated with fruit production and final dry biomass. Expectedly, the number of flowers, the number of fruits and final dry biomass showed significant positive correlations in female plants.

To take these correlations among fitness traits into account, we tested the effect of our experimental treatment in a multivariate LMM. The multivariate analysis confirmed our findings from the univariate LMMs. Pollen donor identity affected multivariate fitness significantly (Table 2), outbred plants performed better than inbred plants in all but two fitness components (the exceptions were female flower numbers and 
Table 3 Correlations between offspring fitness traits, $N=107$ male offspring $(\mathrm{M})$ and 215 female offspring (F)

\begin{tabular}{|c|c|c|c|c|c|c|c|c|c|c|c|}
\hline & \multicolumn{2}{|c|}{ Germination time } & \multicolumn{2}{|c|}{ Vegetative growth } & \multicolumn{2}{|c|}{ Age at flowering } & \multicolumn{2}{|c|}{ Number of flowers } & \multirow{2}{*}{$\begin{array}{c}\text { Number of fruits } \\
F\end{array}$} & \multicolumn{2}{|c|}{ Total dry biomass } \\
\hline & $M$ & $F$ & Day 21 & Day 60 & $M$ & $F$ & $M$ & $F$ & & $M$ & $F$ \\
\hline \multicolumn{12}{|c|}{ Germination time } \\
\hline M & & - & -0.321 & 0.070 & 0.082 & - & 0.168 & - & - & 0.189 & - \\
\hline $\mathrm{F}$ & - & & -0.364 & 0.004 & - & -0.080 & - & 0.072 & 0.164 & - & -0.011 \\
\hline \multicolumn{12}{|c|}{ Vegetative growth } \\
\hline Day 21 & 0.001 & $<0.001$ & & -0.139 & -0.575 & -0.473 & -0.222 & 0.048 & -0.137 & -0.063 & 0.146 \\
\hline Day 60 & 0.474 & 0.951 & $<0.001$ & & 0.206 & 0.086 & -0.089 & -0.123 & -0.185 & 0.256 & -0.180 \\
\hline \multicolumn{12}{|c|}{ Age at flowering } \\
\hline $\mathrm{M}$ & 0.401 & - & $<0.001$ & 0.033 & & - & 0.028 & - & - & 0.097 & - \\
\hline $\mathrm{F}$ & - & 0.245 & $<0.001$ & 0.212 & - & & - & -0.139 & 0 & - & -0.163 \\
\hline \multicolumn{12}{|c|}{ Number of flowers } \\
\hline M & 0.084 & - & 0.022 & 0.363 & 0.773 & - & & - & - & 0.129 & - \\
\hline $\mathrm{F}$ & - & 0.296 & 0.482 & 0.073 & - & 0.042 & - & & 0.572 & - & 0.250 \\
\hline \multicolumn{12}{|c|}{ Number of fruits } \\
\hline $\mathrm{F}$ & - & 0.016 & 0.044 & 0.007 & - & 0.995 & - & $<0.001$ & & - & 0.340 \\
\hline \multicolumn{12}{|c|}{ Total dry biomass } \\
\hline $\mathrm{M}$ & 0.051 & - & 0.518 & 0.008 & 0.318 & - & 0.185 & - & - & & - \\
\hline $\mathrm{F}$ & - & 0.874 & 0.032 & 0.008 & - & 0.017 & - & $<0.001$ & $<0.001$ & - & \\
\hline
\end{tabular}

Spearman's rank correlation coefficients are shown above the diagonal and error probabilities (for the null hypothesis that the correlation coefficient is equal to zero) below the diagonal. Bold values indicate significant correlations (35 tests, $\alpha=0.014$ after Bonferroni correction).

male total dry biomass, see Table 1). For some traits, this effect depended on the sex of the plant (significant interaction between pollen donor and offspring sex, Table 2).

\section{Inbreeding depression}

We determined inbreeding depression $(\delta)$ comparing offspring from inbred and outbred crosses of the same maternal plant (Figure 2). We calculated $\delta$ separately in male and female plants for all fitness traits that differed significantly between the sexes (see Table 2). All but two fitness traits showed positive inbreeding depression, with significant values for the two vegetative growth measures and for the age at flowering (Figure 2). The number of flowers in female offspring and final dry biomass of male offspring showed nonsignificant negative values of inbreeding depression. Inbreeding depression on the number of flowers in female offspring was correlated with inbreeding depression on the number of fruits $\left(r_{P}=0.78, P=0.0003\right)$. All other values of inbreeding depression were not significantly correlated within maternal plants (91 tests, $\alpha=0.0006$ after Bonferroni correction, all $P>0.008)$. Total fitness showed significant inbreeding depression in males (22\%) and in females (14\%, see Figure 2). Inbreeding depression on germination success, age at flowering, and numbers of flowers and fruits explained most of this variation in inbreeding depression on total fitness, and the impact of some of these traits differed between the sexes (Figure 2).

\section{Paternity in two-donor pollinations}

In two-donor pollinations, the unrelated male sired on average $57.1 \%$ of the offspring (range: $0-100 \%, N=20$ females). There was thus wide variation with the unrelated male siring most or all offspring in half of the families. We applied generalized LMMs with binomial error to test if the relatedness of the two pollen donors to the mother influenced the fertilization success of unrelated males. The dependent variable was the number of offspring sired by the unrelated male, and the binomial denominator was the number of offspring successfully typed in the microsatellite analysis. We entered maternal family as a random factor to account for similarities between sisters. In the first model, the fixed effects were (1) the relatedness of the brother to the mother, (2) the relatedness of the unrelated pollen donor to the mother and (3) their interaction. Only the relatedness of the brother to the mother $\left(r_{\mathrm{B}}\right)$ had a significant effect on the fertilization success of unrelated males (Figure 3a; $\mathrm{b} \pm$ s.e. $=4.414 \pm 0.665, \mathrm{~F}_{1,6.8}=44.05$, $P<0.001$, estimated dispersion parameter $=0.743$ ). In a second model, we found that the difference between a mother's relatedness to her brother and to the unrelated male $(\Delta r)$ also had a significant effect on the fertilization success of unrelated males (Figure $3 b$; $\mathrm{b} \pm$ s.e. $=2.867 \pm 1.200, \mathrm{~F}_{1,7.2}=5.70, P=0.047$, estimated dispersion parameter $=2.226$ ). The unrelated pollen donor sired more offspring in two-donor pollinations if the difference in relatedness of the two males to the female was large. This seemed to be caused by variation in relatedness values of brothers, rather than those of the unrelated males. The unrelated pollen donor had a higher fertilization success if the brother was genetically more similar to the mother.

We detected a difference in germination success between inbred and outbred offspring (Table 2), and this may have caused the observed paternity bias among offspring plants. We therefore repeated the above analyses with two more conservative estimates of paternity for the unrelated male. First, we assigned paternity to seeds that failed to germinate (and were hence not microsatellite typed), according to the germination success of inbred and outbred seeds from 


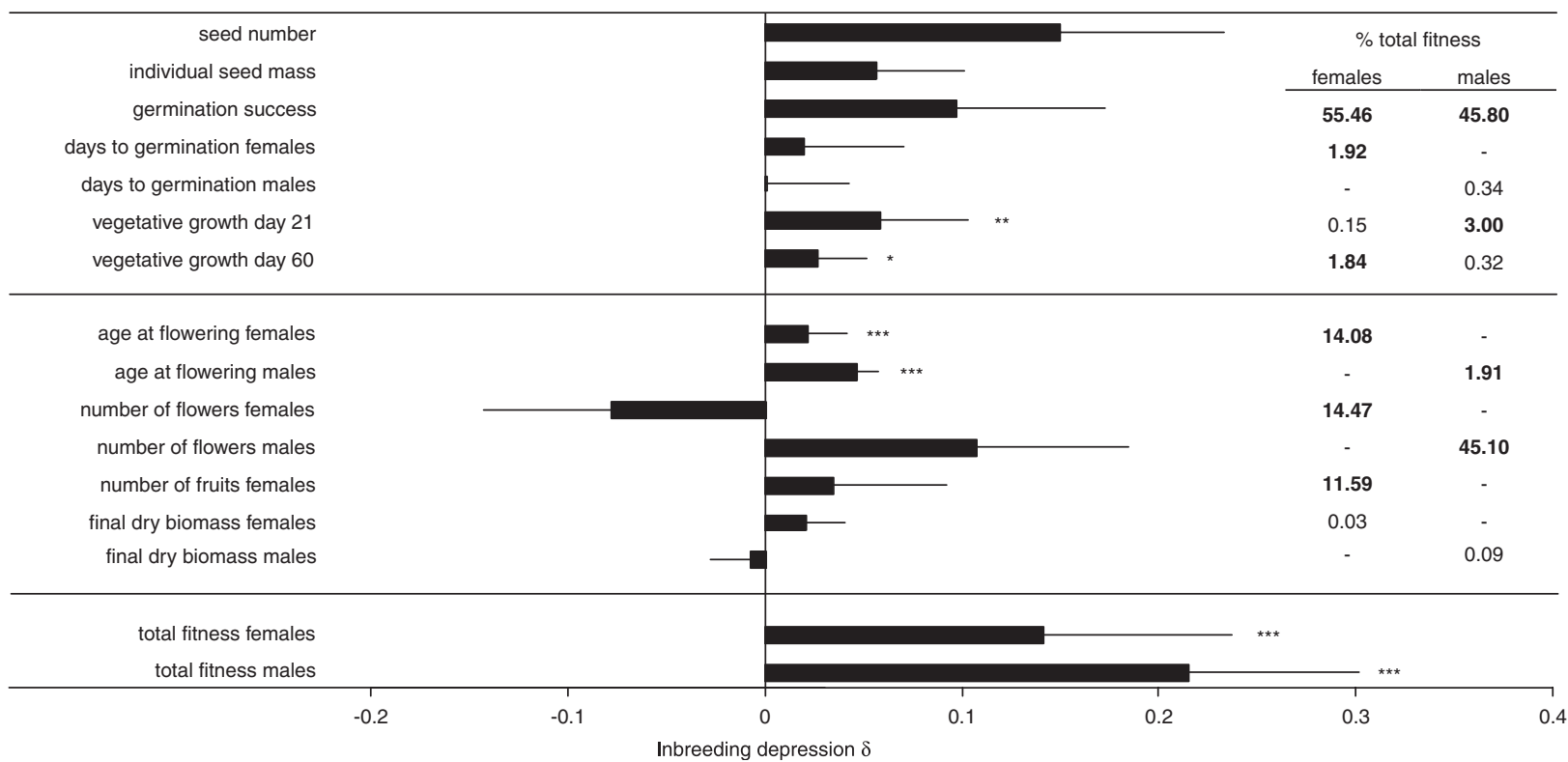

Figure 2 Inbreeding depression $(\delta)$ among offspring from experimental crosses in S. latifolia. Positive values indicate that outbred offspring had higher fitness, whereas negative values show that inbred offspring had higher fitness. Bars represent mean values of $\delta(N=20$ maternal plants), error bars show the standard error of the mean. The significance of $\delta$ is estimated by the factor donor identity (brother or unrelated male) in the ANOVA analyses of seed production (see text), and the generalized linear mixed model (GLMM) analyses of all other fitness traits (see text and Table 2): ${ }^{*}{ }^{* *}$ and ${ }^{* * *}$ signify $P<0.05, P<0.01$, and $P<0.001$, respectively. Values on the right list indicate the percentage of variance in inbreeding depression on total fitness explained by each offspring fitness component. This was obtained from an accumulated analysis of variance of inbreding depression on female total fitness (total variance: 3.19 , unexplained residual variance: 0.01 ), and of inbreding depression on male total fitness (total variance: 3.28 , unexplained residual variance: 0.11 ). Bold values were significantly larger than zero.
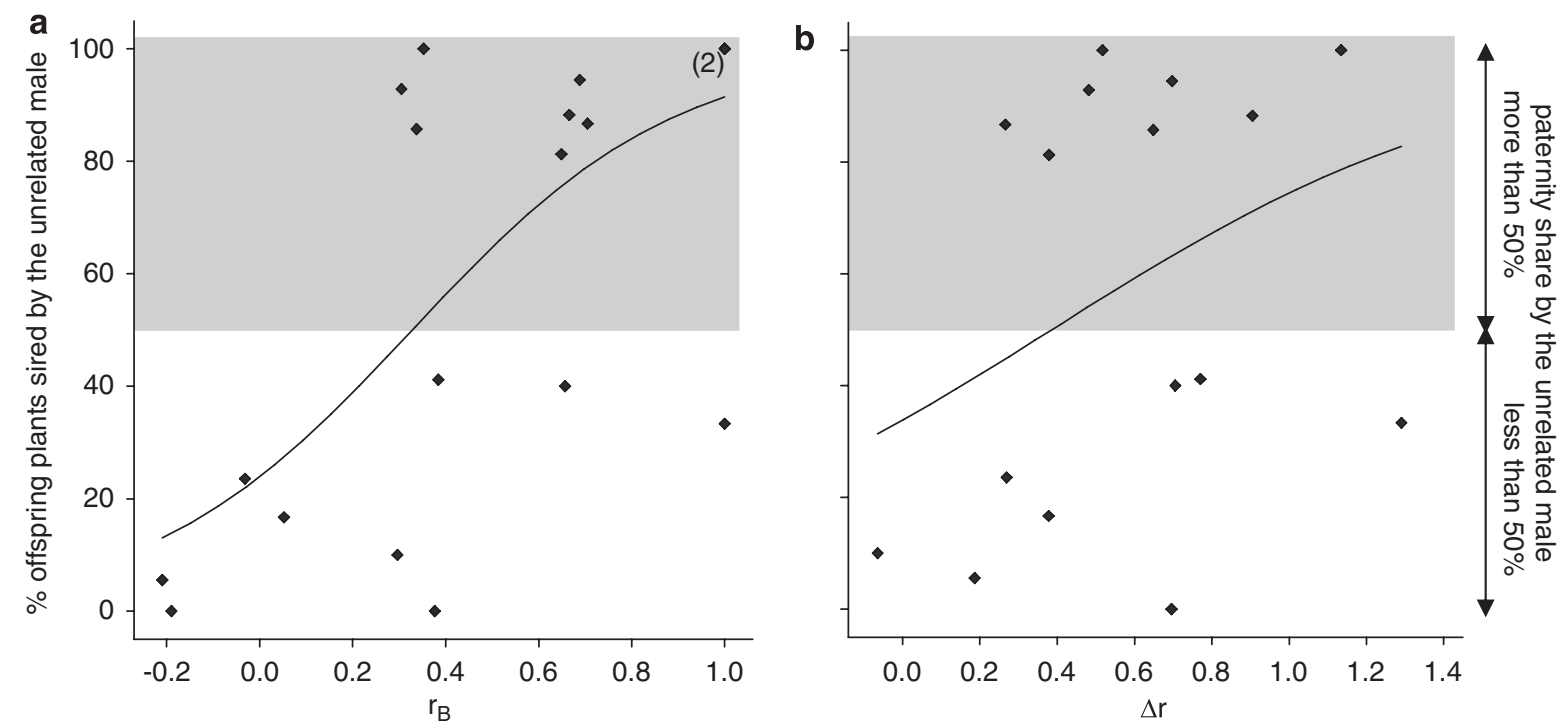

Figure 3 Fertilization bias in two-donor crosses, in which a 1:1 mixture of pollen from a brother and an unrelated male were simultaneously applied. (a) The effect of relatedness between the maternal plant and the brother $\left(r_{\mathrm{B}}\right)$ on the fertilization success of the unrelated pollen donor $(N=18$ crosses, (2) indicates two overlapping data points). (b) The effect of the difference between the maternal plant's relatedness with the brother and with the unrelated male $(\Delta r)$ on the fertilization success of the unrelated male $(N=16$ crosses). Relatedness refers to Queller and Goodnight's $r$. The regression lines show predicted values from a logistic regression.

the same mother in the single-donor crosses (see Materials and methods). The unrelated male still sired more offspring, if the brother was more related to the maternal plant (significant effect of $r_{\mathrm{B}}$; $\mathrm{b} \pm$ s.e. $=1.935 \pm 0.460, \mathrm{~F}_{1,6.9}=17.69, P=0.004$, estimated dispersion parameter $=1.224)$. The effect of $\Delta r$ was not significant $\left(\mathrm{F}_{1,8.3}=3.31, P=0.105\right.$, estimated dispersion parameter $=2.377$ ). Second, we assigned all seeds that failed to germinate to the brother (under the assumption that only the more closely related male would lose offspring at this stage). Even under this very conservative assumption, we still detected 
a significant effect of $r_{\mathrm{B}}$ on the paternity bias (b \pm s.e. $=2.330 \pm 0.634, \mathrm{~F}_{1,7.5}=13.52, P=0.007$, estimated dispersion parameter $=1.921)$. And similar to our original analysis, the alternative model showed a significant effect of $\Delta r\left(\mathrm{~b} \pm\right.$ s.e. $=2.276 \pm 0.957, \mathrm{~F}_{1,7.5}=5.66, P=0.047$, estimated dispersion parameter $=1.913$ ).

\section{Discussion}

S. latifolia occurs in meta-populations that often include also very small populations. Seeds disperse by gravity, leading to a potentially frequent risk of inbreeding under natural circumstances (Richards, 2000). On the other hand, naturally pollinated fruits are often sired by several fathers (Teixeira and Bernasconi, 2007), and pollen carry-over may hence provide the opportunity for post-pollination pre- or post-zygotic selection against inbreeding. Our study demonstrates costs of inbreeding and paternal genetic effects on fitness in S. latifolia. In addition, we find a paternity bias towards the less related pollen donor and hence evidence for a post-pollination mechanism that reduces inbreeding.

\section{The costs of inbreeding}

This study presents, to our knowledge, the most detailed analysis of inbreeding depression in S. latifolia; moreover, most of the current knowledge on inbreeding depression in plants stem from uniparental inbreeding in hermaphroditic species, although here we investigated biparental inbreeding in a dioecious species. We measured seed and plant performance during a number of life-cycle stages in both sexes, and found positive inbreeding depression for most of the investigated fitness traits. In general, offspring sired by the unrelated male performed better than offspring arisen from one generation of sib mating in replicate crosses with the same female plant. This difference was significant for early growth measurements and for the age at which plants started to flower, as well as for overall fitness. The variation in inbreeding depression on overall fitness was mainly explained by inbreeding depression on germination success and on flower and fruit production. Inbreeding depression has previously been reported in other populations of the same species (on seed germination; Richards, 2000), and in congeneric species with mixed mating systems, for example, S. acaulis (Delph, 2004), S. vulgaris (Glaettli and Goudet, 2006) and S. flos-cuculi (L.) Clairv. (formerly Lychnis flos-cuculi L.; Hauser and Loeschcke, 1995).

Interestingly, inbred females produced more flowers than outbred females, whereas in males, inbred plants produced fewer flowers than outbred plants. An explanation for this may be the existence of sexually antagonistic selection pressures on flower numbers in this species. Male S. latifolia plants are probably under sexual selection for high flower numbers, whereas fecundity selection in females favours large flowers, and hence low flower numbers (due to a negative genetic correlation between these two traits; Steven et al., 2007). Consequently, S. latifolia shows a strong sexual dimorphism for floral display size. The negative values of inbreeding depression on flower numbers thus indicate that outbred daughters are in fact superior over inbred daughters.
Significant levels of inbreeding depression are consistent with high genetic loads being maintained in outcrossing species (Husband and Schemske, 1996), such as S. latifolia. Although Husband and Schemske (1996) suggested that high inbreeding depression should occur either early (on seed traits) or late in the life cycle (at reproduction), our study revealed generally mild $(<0.20$; for example, Mayer et al., 1996) inbreeding depression on all investigated traits. Significant effects, however, were restricted to an intermediate stage, at the time of early growth. We followed offspring fitness throughout most of the first flowering season, but as S. latifolia can flower in one or more subsequent years, cumulative inbreeding depression may be stronger if measured on the entire life cycle. Further, we measured inbreeding depression under seminatural and benign conditions in the absence of competition with other plants. The expression of inbreeding depression can be influenced by environmental conditions (Dudash, 1987; Hayes et al., 2005; Paschke et al., 2005), and by competition with other plants both through density (Wolfe, 1993) and frequency of inbred and outbred individuals (Cheptou and Schoen, 2003). Thus, our results may underestimate inbreeding depression in natural stands. Our findings and the report of strong inbreeding depression on seed germination in other populations of S. latifolia (Richards, 2000) suggest that we may expect the evolution of a mechanism to reduce fertilization by related pollen in this species.

\section{Heritable genetic effects on fitness}

The family origin of the paternal plant significantly affected all but two offspring fitness measures. This suggests at least paternally inherited genetic components of these traits. However, our experimental setup was not specifically designed to test for the heritability of fitness traits. In particular, maternal genetic effects may also be present, but we could not separate them from direct maternal effects, which we accounted for in the random model. Only total dry biomass was affected by maternal family, but in this model, the random term of maternal identity was bound to zero. In all other models, the random term most likely explained both genetic and direct maternal effects. Paternal genetic effects on fitnessrelated traits, as observed in our study, are not uncommon in plants (Mazer and Gorchov, 1996). They have been shown, for example, for leaf dimensions in Solidago altissima (Schmid and Dolt, 1994), growth and flower display in Raphanus sativus (Marshall and Whittaker, 1989) or seed mass and seedling growth in Campsis radicans (Bertin and Peters, 1992). Our data thus indicate that besides the non-heritable genetic effect on fitness through inbreeding, there are heritable paternal genetic effects in S. latifolia. Both benefits of good genes and of compatible genes have an important function in the evolution of pollen receipt and pollen or embryo selection mechanisms, as female plants should prefer as sires dissimilar males, but also males of high genetic quality. This may be relevant for $S$. latifolia, as male reproductive success varies more than female reproductive success in natural stands (Wright and Meagher, 2004), indicating stronger sexual selection in males. The relative importance of both genetic benefits in this system, as in most plants in general (Delph and Havens, 1998) remains to be shown. 
Paternity bias in response to relatedness among mates in two-donor crosses

The paternity success of the unrelated male increased significantly, the greater its relative genetic dissimilarity to the female. This effect depended on the relatedness between the maternal plant and the sibling male, rather than on her relatedness with the unrelated male. These results support our hypothesis that the outcome of postpollination pollen competition and/or embryo selection depends on the genetic similarity between the mating partners. In S. latifolia, pollen carry-over (Teixeira and Bernasconi, 2007) and post-pollination selection mechanisms may hence bear the potential for a reduction of inbreeding in populations, where pollinations between related plants are frequent. Importantly, our finding is consistent with another study in S. latifolia (formerly $S$. alba), which found that gene flow was higher into experimental full-sib patches than into patches consisting of unrelated individuals (Richards, 2000). In that study, female plants could be pollinated from a brother at $0.5 \mathrm{~m}$ distance or an unrelated male at $20 \mathrm{~m}$ distance. Paternity analysis revealed more fertilizations by the unrelated male at $20 \mathrm{~m}$ distance than expected at random. This confirms that paternity success depends on relatedness among parents also in other populations of S. latifolia, which was referred to as a possible mechanism of 'genetic rescue'. This mechanism as a last escape from inbreeding is not restricted to plant species. Our result is also consistent with the finding in another S. latifolia population, where paternity success of focal males after hand pollination was significantly more repeatable between females, which were full sisters (implying similar relatedness between mates), than with a female unrelated to the previous ones (Teixeira et al., in press). Post-mating selection has also been found and shown to reduce inbreeding in crickets (for example, Simmons et al., 2006) and in birds (for example, Foerster et al., 2006).

In about half of the crosses, it was in fact the related male, which sired a majority of the offspring. Under some conditions, inbred mating may provide a kin selection benefit by increasing transmission of related genes (Parker, 2006). In a full sib mating without opportunity costs, it would be favourable for females to mate with a sibling male if inbreeding depression $\delta$ was smaller than $1 / 3$. For males, sibling matings are adaptive even under higher inbreeding depression $(\delta<2 / 3$; Parker, 2006). Interestingly, we observed an increase of fertilization bias towards the unrelated male with increasing relatedness between the maternal plant and the sibling pollen donor. This relatedness was larger than 0.3 in all crosses, where the unrelated male sired more than $50 \%$ of the offspring. This finding, and the fact that most estimates of $\delta$ in this study fall below 0.33 suggest that it would be valuable to jointly investigate the relative benefits of inclusive fitness and inbreeding avoidance in this system.

Our estimates of relatedness show considerable sampling variance, because we had only three autosomal microsatellite markers available. However, it seems unlikely that this sampling error biased the data in favour of our working hypotheses. We consider it more likely that the error induced unspecific variance, and that we might find more pronounced results with more precise estimates of relatedness. Developing more microsatellite markers for this model system will prove highly fruitful for future studies on the effect of genetic similarity on paternity success.

In S. latifolia, it is not known if the observed paternity bias is induced pre- or post-zygotically, and future studies are needed to estimate which of the potential mechanisms (pollen selection, selective embryo abortion, competition among developing embryos or early-acting inbreeding depression; Rigney, 1995) may prevail. Although differential embryo abortion may favour outbred progeny, the widespread existence of prezygotic self-incompatibility mechanisms in plants (Nasrallah, 2002) and the general finding that self-pollen achieves less paternity success than outcross pollen (reviewed by Bernasconi, 2003) indicate that differential pollen success with a simple genetic basis is indeed possible, and may be less costly to the female plant than embryo abortion.

Early-acting inbreeding depression or embryo abortion are unlikely to account fully for the effect detected in our study. First, we found no evidence for general inbreeding depression on embryos, as seed numbers did not differ significantly between inbred and outbred crosses. Although we did not assess the number of undeveloped ovules/seeds, crosses were replicated within plants, accounting for variation among individuals in number of ovules. Second, to account for the observed inbreeding depression on germination success, we conducted a conservative analysis where we assigned all seeds that did not germinate to the brother, and still found a paternity bias towards the unrelated male. However, in mixed crosses, competition within a fruit may have induced the selective abortion of inbred embryos (De Jong and Klinkhamer, 2005). This would reduce the number of inbred seeds, while not necessarily reducing the amount of seeds formed. We conclude that the paternity bias among seeds may arise from postpollination pollen selection and/or from selective embryo abortion. One or both of these mechanisms resulted in reduced effective inbreeding in mixed crosses and increased the adaptive value of the progeny for maternal plants. This will ultimately affect local rates of inbreeding, sib competition, but also genetic structure and pollen-mediated gene flow in natural stands of S. latifolia (Richards, 2000).

\section{Acknowledgements}

We thank Jérôme Goudet, Jelmer Elzinga, Lukas Keller, Bernhard Schmid, Doug Taylor and the reviewers for valuable comments, and Rui Candeias, Céline Jolivet and Ana Ribeiro for practical help. We acknowledge financial support from Swiss National Science Foundation (no. PPOOA-102944/1 to GB) and the Commission Egalité of Lausanne University (to ST).

\section{References}

Ågren J, Schemske DW (1993). Outcrossing rate and inbreeding depression in two annual monoecious herbs, Begonia hirsuta and B. semiovata. Evolution 47: 125-135. 
Aizen M, Searcy K, Mulcahy D (1990). Among- and withinflower comparisons of pollen tube growth following self- and cross-pollinations in Dianthus chinensis (Caryophyllaceae). Am J Bot 77: 671-676.

Bateman AJ (1956). Cryptic self-incompatibility in the wall flower: Cheiranthus cheiri L. Heredity 10: 257-261.

Becker JD, Boavida L, Carneiro J, Haury M, Feijó J (2003). Transcriptional profiling of Arabidopsis tissues reveals the unique characteristics of the pollen transcriptome. Plant Physiol 133: 713-725.

Bernasconi G (2003). Multiple paternity in flowering plants and its evolutionary consequences. Persp Plant Ecol Evol Syst 6: 149-158.

Bernasconi G, Ashman TL, Birkhead T, Bishop J, Grossniklaus U, Kubli E et al. (2004). Evolutionary ecology of the prezygotic stage. Science 303: 971-975.

Bernasconi G, Paschke M, Schmid B (2003). Diversity effects in reproductive biology. Oikos 102: 217-220.

Bertin RI, Peters PJ (1992). Paternal effect on offspring quality in Campsis radicans. Am Nat 140: 166-178.

Carr D, Dudash MR (2003). Recent approaches into the genetic basis of inbreeding depression in plants. Phil Trans $R$ Soc Lond B 358: 1071-1084.

Charlesworth D, Charlesworth B (1987). Inbreeding depression and its evolutionary consequences. Annu Rev Ecol Syst 18: 237-268.

Cheptou PO, Schoen DJ (2003). Frequency-dependent inbreeding depression in Amsinckia. Am Nat 162: 744-753.

Cruzan MB, Barrett SCH (1996). Postpollination mechanisms influencing mating patterns and fecundity: an example from Eichhornia paniculata. Am Nat 147: 576-598.

De Jong TJ, Klinkhamer PGL (2005). Evolutionary Ecology of Plant Reproductive Strategies. Cambridge University Press: Cambridge.

Delph LF (2004). Testing for sex differences in biparental inbreeding and its consequences in a gynodioecious species. Am J Bot 91: 45-51.

Delph LF, Havens K (1998). Pollen competition in flowering plants. In: Birkhead T, Møller A (eds). Sperm Competition and Sexual Selection. Academic Press: San Diego, pp 149-173.

Doyle JJ, Doyle JL (1990). Isolation of plant DNA from fresh tissue. Focus 12: 13-15.

Dudash MR (1987). Relative fitness of selfed and outcrossed progeny in a self-compatible, protrandous species, Sabatia angularis L. (Gentianaceae): a comparison in three environments. Am J Bot 74: 648 .

Dudash MR, Carr DE (1998). Genetics underlying inbreeding depression in Mimulus with contrasting mating systems. Nature 393: 682-684.

Fishman L (2001). Inbreeding depression in two populations of Arenaria uniflora (Caryophyllaceae) with contrasting mating systems. Heredity 86: 184-194.

Foerster K, Valcu M, Johnsen A, Kempenaers B (2006). A spatial genetic structure and effects of relatedness on mate choice in a wild bird population. Mol Ecol 15: 4555-4567.

Glaettli M, Goudet J (2006). Variation in the intensity of inbreeding depression among successive life-cycle stages and generations in the gynodioecious Silene vulgaris (Caryophyllaceae). J Evol Biol 19: 1995-2005.

Glaettli M, Pescatore L, Goudet J (2006). Proximitydependent pollen performance in Silene vulgaris. Ann Bot 98: 431-437.

Hardy OJ, Vekemans X (2002). SPAGEDi: a versatile computer program to analyse spatial genetic structure at the individual or population levels. Mol Ecol Notes 2: 618-620.

Hauser TP, Loeschcke V (1995). Inbreeding depression in Lychnis flos-cuculi (Caryophyllaceae): effects of different levels of inbreeding. J Evol Biol 8: 589-600.

Hauser TP, Siegismund HR (2000). Inbreeding and outbreeding effects on pollen fitness and zygote survival in Silene nutans (Caryophyllaceae). J Evol Biol 13: 446-454.
Hayes CN, Winsor J, Stephenson A (2005). Environmental variation influences the magnitude of inbreeding depression of Cucurbita pepo ssp. texana (Cucurbitaceae). J Evol Biol 18: 147-155.

Hoffman JI, Forcada J, Trathan PN, Amos W (2007). Female fur seals show active choice for males that are heterozygous and unrelated. Nature 445: 912-914.

Husband B, Schemske D (1996). Evolution and the magnitude and timing of inbreeding depression in plants. Evolution $\mathbf{5 0}$ 54-70.

Jolivet C, Bernasconi G (2007). Molecular and quantitative genetic differentiation in European populations of Silene latifolia (Caryophyllaceae). Ann Bot 100: 119-127.

Jones KN (1994). Nonrandom mating in Clarkia gracilis (Onagraceae): a case of cryptic incompatibility. Am J Bot 81: 195-198.

Keller L, Waller D (2002). Inbreeding effects in wild populations. Trends Ecol Evol 17: 230-241.

Lande R, Schemske D (1985). The evolution of self-fertilization and inbreeding depression in plants. Genetic models. Evolution 39: 24-40.

Marshall DL, Whittaker KL (1989). Effects of pollen donor identity on offspring quality in wild radish Raphanus sativus. Am J Bot 76: 1081-1088.

Mayer SS, Charlesworth D, Meyers B (1996). Inbreeding depression in four populations of Collinsia heterophylla Nutt (Scrophulariaceae). Evolution 50: 879-891.

Mazer SJ, Gorchov DL (1996). Parental effects on progeny phenotype in plants: distinguishing genetic and environmental causes. Evolution 50: 44-53.

McCauley D (1997). The relative contributions of seed and pollen movement to the local genetic structure of Silene alba. J Hered 88: 257-263.

Mitchell RJ, Karron JD, Holmquist KG, Bell JM (2005). Patterns of multiple paternity in fruits of Mimulus ringens (Phrymaceae). Am J Bot 5: 885-890.

Nasrallah J (2002). Recognition and rejection of self in plant reproduction. Science 296: 305-308.

Parker GA (2006). Sexual conflict over mating and fertilization: an overview. Phil Trans $R$ Soc Lond $B$ 361: 235-259.

Paschke M, Bernasconi G, Schmid B (2005). Effects of inbreeding and pollen donor provenance and diversity on offspring performance under environmental stress in the rare plant Cochlearia bavarica. Basic Appl Ecol 6: 325-338.

Pfahler P (1965). Fertilization ability of maize pollen grains: pollen source. Genetics 52: 513-520.

Queller DC, Goodnight KF (1989). Estimating relatedness using genetic markers. Evolution 43: 258-275.

Richards CM (2000). Inbreeding depression and genetic rescue in a plant metapopulation. Am Nat 155: 383-394.

Rigney LP (1995). Postfertilization causes of differential success of pollen donors in Erythronium grandiflorum (Liliaceae). Am J Bot 82: 578-584

Schmid B, Dolt C (1994). Effects of maternal and paternal environment and genotype on offspring phenotype in Solidago altissima L. Evolution 48: 1525-1549.

Simmons LW, Beveridge M, Wedell N, Tregenza T (2006). Postcopulatory inbreeding avoidance by female crickets only revealed by molecular markers. Mol Ecol 15: 3817-3824.

Steven JC, Delph LF, Brodie ED (2007). Sexual dimorphism in the quantitative-genetic architecture of floral, leaf, and allocation traits in Silene latifolia. Evolution 61: 42-57.

Teixeira S, Bernasconi G (2007). High prevalence of multiple paternity within fruits in natural populations of Silene latifolia, as revealed by microsatellite DNA analysis. Mol Ecol 16: $4370-4379$.

Teixeira S, Bernasconi G (2008). Effects of inbred/outbred crosses on progeny sex ratio in Silene latifolia (Caryophyllaceae). New Phyt 178: 448-456. 
Teixeira S, Burkhardt A, Bernasconi G (in press). Genetic variation among females affects paternity in a dioecious plant. Oikos; doi:10.1111/j.2008.0030-1299.16450.x.

Waser N, Price M (1993). Crossing distance effects on prezygotic performance in plants: an argument for female choice. Oikos 68: 303-308.
Wolfe LM (1993). Inbreeding depression in Hydrophyllum appendiculatum: role of maternal effects, crowding, and parental mating history. Evolution 47: 374-386.

Wright JW, Meagher TR (2004). Selection on floral characters in natural Spanish populations of Silene latifolia. J Evol Biol 17: 382-395.

Supplementary Information accompanies the paper on Heredity website (http://www.nature.com/hdy) 